\title{
Orthograde Apical Application of an MTA Plug in a Tooth without Constriction - A Case Report
}

\author{
Gusiyska A. \\ Assistant Professor of the Department of Conservative Dentistry, Faculty of Dental Medicine, Medical University-Sofia, Bulgaria
}

\begin{abstract}
The periapical area in teeth with chronic lesions is characterized by changes in the adjacent bone structure and periodontal ligaments, as well as in the cement and dentine. In a large percentage of cases, the apical physiological constriction is ether absent or expanded. The absence of a constriction makes it a challenge to achieve satisfactory treatment results.The present case report describes the re-treatment of a case of a mandibular molar, complicated by lack of constriction and a separated endodontic instrument. Mineral trioxide aggregate (MTA) was used for a 5-mm apical plug to avoid overfilling of the sealer when the root canal was definitely obturated. The periapical radiographs showed satisfactory images of periapical bone density and the tooth was asymptomatic on precision. MTA is proved to be an appropriate material for apical sealing in cases with resorption, as it leads to avoidance of apical surgical procedures with a similar prognostic outcome.
\end{abstract}

Keywords: apical barrier, apical constriction, apical root resorption,mineral trioxide aggregate (MTA), re-treatment.

\section{Introduction}

The minor apical foramen should be maintained at its initial position and size after chemo-mechanical endodontic procedures. If the apical constriction is breached and transported, cleaning procedures are compromised and obturation is significantly difficult to carry out well. Apical root resorption is a pathologic condition of the inflammatory response, characterized by the processes of cement and/or dentine depletion, resulting from the activity of resorptive cells, called dentoclasts (a subclass of the osteoclasts) ${ }^{6,7,12}$. Treatment of the apical resorptive processes is likely to occur through removal of the pulp and granulation tissue, as well as interruption of the blood supply to these tissues, which is necessary for the development of resorbing cells. In many cases with incomplete root canal treatment, there are resorptive changes in the apical zone. One of the major challenges in endodontic treatment of teeth with open apices due to resorption is achieving effective debridement, canal disinfection and subsequent sealing of the root canal space. The key point is to form an apical barrier or a stop against which one can place the sealer and gutta-percha, while avoiding over-extrusion ${ }^{17,21}$. Mineral trioxide aggregate (MTA) is a reliable material due to its biocompatibility and good sealing properties, which providesopportunities for the regeneration of periapical tissues,such as periodontal ligament, bone and cementum ${ }^{1,2,15}$.

These properties makeMTA a suitable material for the management of apical-zone sealing in cases with resorption and without physiological constriction. The present case report describes are-treatmentcaseof a mandibular molar,complicated by lack of constriction and a separated endodontic instrument.

\section{Case Report}

A 34-year-old female patient was referred for endodontic treatment of tooth \#46 because of a separated endodontic instrument into the mesial root, which was observed on the initial radiograph (Figure 1). The patient's chief complaint was mild pain inthe lower right back region during chewing.
She gave history of a root canal treatment on thesame tooth 4 yearsearlier. There was no other relevant medical history.Based on the clinical and radiographic findings, root canal therapy was initiated. Arubber dam was placed and the tooth was accessed without theneed foranesthesia.Crowndown preparation was performed for orthograde endodontic treatment. The mesiobuccal canal was negotiated with $\mathrm{C}$-file $\# 0.06$ and the separated instrument was removed under magnification with adental operating microscope (16x, Zeiss, Germany), and a control radiograph was done (Figure 2 ). The root canals were cleaned and shaped with ProTaper rotary instruments (Maillefer Dentsply, Switzerland). The mesial canals were prepared up to F3. All of the canals were irrigated with a copious amount of $5.25 \%$ sodium hypochlorite and $17 \%$ EDTA. This was followed by irrigation with $0.9 \%$ saline to remove any remnants of hypochlorite and EDTA. Hemorrhage and exudate from the apical region of the distal canal was observed during the instrumentation, which suggested resorptionexteriorization. The canals were dried with absorbent paper points, and calcium hydroxide paste (ApexCal,IvoclarVivadent, Liechtenstein) was placed in the canals as an intracanal medicament, followed by temporaryrestoration with glass ionomer cement.

The calcium hydroxide paste was removed 10 days later. The complete removal of paste from the root canal walls was accomplished by passive ultrasound irrigation (PUI) and $10 \%$ citric acid, using an endodontic tip (ESI,EMS,Switzerland) for more precise cleaning. Taking into consideration the extent of the apical root resorption, it was decided to perform orthograde MTA obturation of the distal canal space to arrest the resorption.The material was placed into the canals with a MAP System carrier (PD,Switzerland)(Figure3) by the means of a 5-mm apical plug,and was condensed vertically with a handplugger.After radiographic examination of the accuracy of the apical plug (Figure 4) and a setting period, the entire canal andthe medial canals were obturated with Total Fill BC (FKG, Switzerland) (Figure 5). 


\section{International Journal of Science and Research (IJSR) \\ ISSN (Online): 2319-7064}

Index Copernicus Value (2013): 6.14 | Impact Factor (2014): 5.611

The orifices were adhesively sealed and the tooth was definitively restored with light-curing composite, and

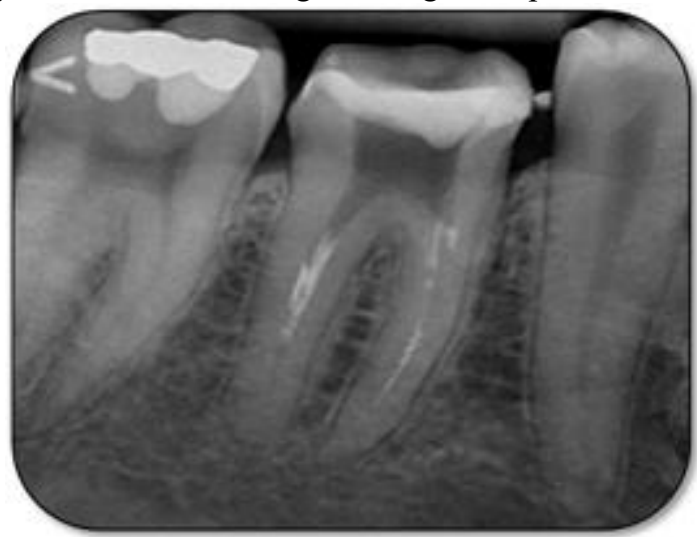

Figurel: Initial radiographic status for tooth $\# 46$.

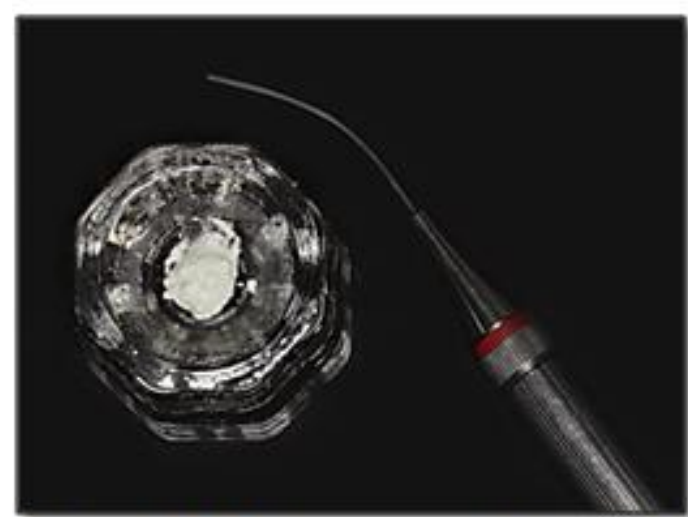

Figure 3: MAP System carier with prepared MTA.

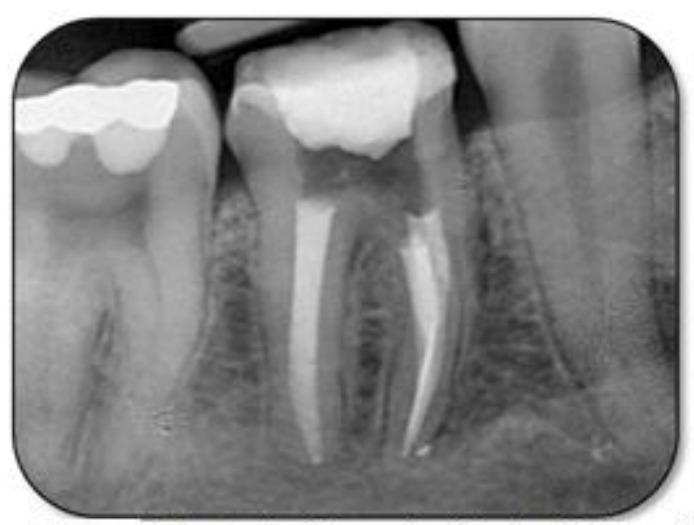

Figure 5:Controlra diograph after final obturation

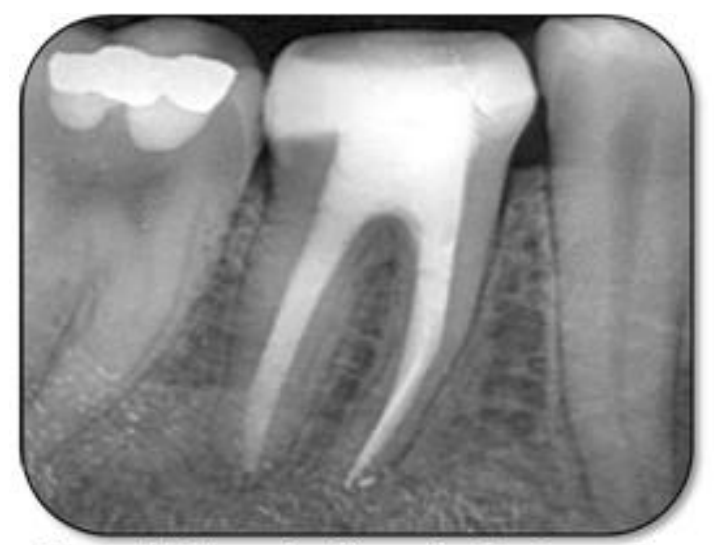

Figure 7: Control radiograph after 3 months prepared for a crown.

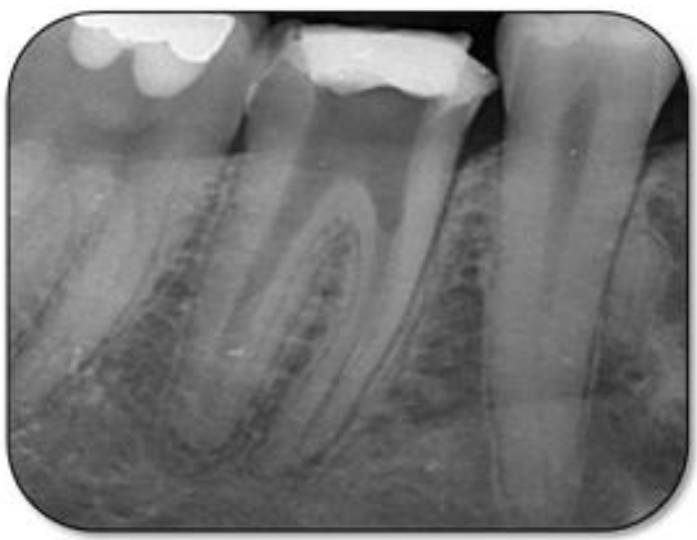

Figure 2: Control radiograph to assess the removal of a separated lentulo.

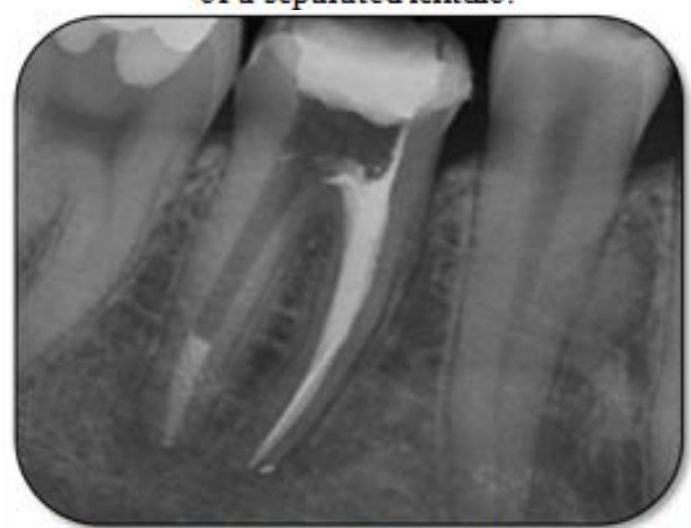

Figure4: Obturation of mesial canals and a 5-mm apical plug of MTA distally.

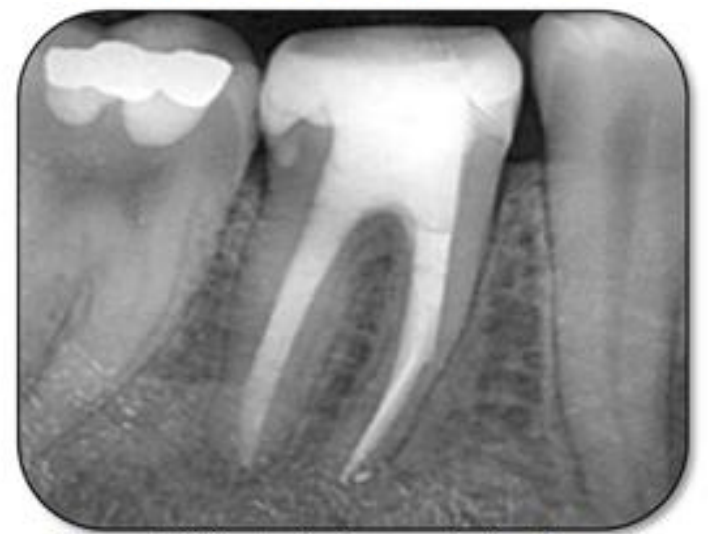

Figure 6: Controlra diograph after 1 month

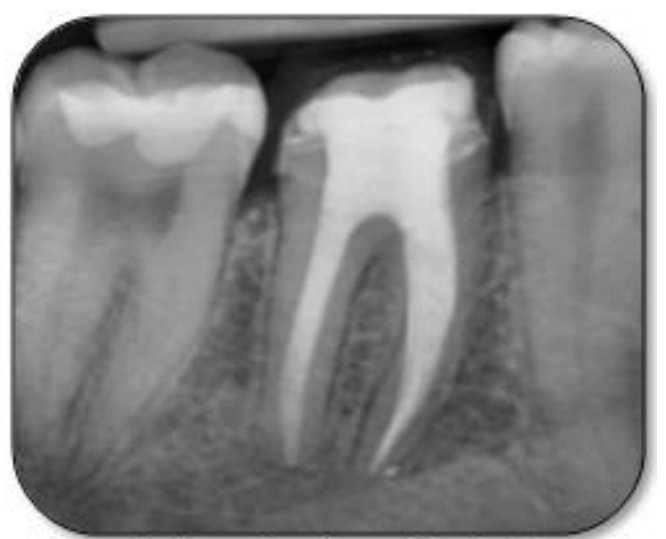

Figure 8: Control radiograph after 6 months

Volume 5 Issue 2, February 2016

www.ijsr.net 


\section{International Journal of Science and Research (IJSR) \\ ISSN (Online): 2319-7064}

Index Copernicus Value (2013): 6.14 | Impact Factor (2014): 5.611

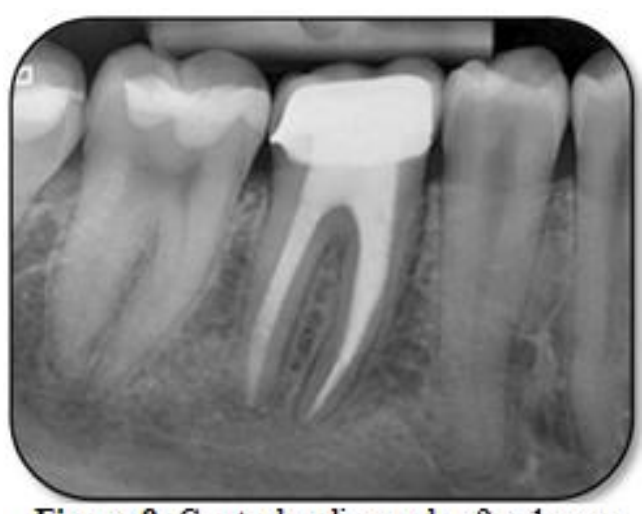

Figure 9: Control ra diograph after 1 year.

The patient was recalled after 1month (Figure 6), 3 months (Figure 7), and 6 months (Figure 8) for clinical and radiographic follow-up.Clinical examination of tooth \#46 was functional without sensitivity to percussion or palpation. The tooth showed normal physiologic mobility and no periodontal pockets on probing. The periapical radiographs showed satisfactory periapical bone density with no sign of periapical radiolucencies and no further progression of the resorptive process around the distal apical zone. The treatment was definitivelyfinished with a crown.After 1 year the patient was recalled again, and the tooth was found to be symptom-free. No percussion sensitivity was observed. The periapical radiograph showed a satisfactory image (Figure 9).

\section{Discussion}

Not every resorptive process in the apical zone can be observed on aninitial periapical radiograph. Only thickening of the periodontal ligament space was discovered, andthe resorption process in the apical zone in this case was detected clinically and measured withendodontic instruments because of the superimposition of the structures.

Three-dimensional sealing of the endodontic space is one of the main goals of root canal treatment and is essential for preventing apical and coronal leakage ${ }^{15}$.One of the characteristics of a biomaterial is its ability to form an apatite-like layer on its surface when it comes into contact with physiologic fluids in vivo or with stimulated body fluid in vitro. MTA is a bioactive material that is mainly composed of tricalcium and silicate. Scientific investigations have shown that MTA can release various ions thatconduct and induct hard-tissue formation ${ }^{4,17}$.MTA presents some advantages,including its physical characteristics thatguarantee expansion during the attachment, which favors sealing, and the biological properties ofcalcium hydroxide ${ }^{3,24}$. MTA forms calcium oxide when in contact with water, which then, when in contact with tissue fluids, forms calcium hydroxide and triggers the same repair process in the tissue ${ }^{11}$. Some recentstudies have reported on the success of MTA as a root apical barrier, with rates ranging from $76.5 \%$ to $91 \%{ }^{10,20}$.

Antimicrobial activity of MTA seems to be associated with elevation of $\mathrm{pH}$. Torabinejad et al. observed an initial $\mathrm{pH}$ of 10.2 for MTA, rising to 12.5 in 3 hours, and it is known that a $\mathrm{pH}$ level on theorder of 12.0 can inhibit most microorganisms, including Enterococcus faecalis ${ }^{23}$. When there isa pathway of open communication between the root canal and the periodontium, it must be sealed, with preservation of bacterial leakage. This obturation sealer should be biocompatible and should favor regeneration of the supporting periapical structures ${ }^{26}$.

The apical level of root canal preparation and the border of obturation have been discussed in the literature for several decades. Sealers for the root canal space in cases with advanced resorption havealso been thoroughly examined. Therefore, the development and maintenance of a seal is considered to be a major prerequisite to improving the outcome of root canal treatment. The absence of physiological narrowing is a challenge to the achievement of satisfactory early and late therapeutic results. It makes probable either the overpressing of necrotic, infected material when preparing the endodontic space or the overpressing of the sealer when sealing the root canal.

There is ongoing discussion about the application of calcium hydroxidepaste as an intracanal medicament. Some research has shown that the remains of calcium hydroxide on the dentinal walls had no significant effect on MTA microleakage ${ }^{8}$. In contrast, others have suggested that the remnants react and form calcium carbonate, which interferes with apical sealing ${ }^{19}$.Others have suggested that the combination of calcium hydroxide and MTA in apexification procedures may favorably influence the regeneration of the periodontium ${ }^{9}$. In teeth with chronic periapical lesions, there is a greater prevalence of Gramnegative anaerobic bacteria. When the root canal is mechanically prepared, $35 \%$ of the area remainsuntouched,including the apical bacterial biofilm ${ }^{18}$. Because these areas are not reached by instrumentation, the use of an intracanal medicament such as calcium hydroxide paste is recommended to aid in the elimination of the bacteria and lipopolysaccharides (LPS), and to increase the likelihoodof clinical success ${ }^{13,14,16,25}$.LPS, abacterial endotoxin, causes the formation of periapical lesions. Currently, calcium hydroxide pasteis still a medicament of choice for inactivation and detoxification of thisbacterial endotoxinin vivo ${ }^{22}$. Based on previous research, we used a calcium hydroxide paste in the treatment protocol for thepresent case and observed a successful clinical outcome. Recurrent examinations and radiographs are necessary forfollow-up of the clinical outcome and to avoid the need for surgical interventions 5 .

\section{Conclusion}

MTA is anappropriate material for apical sealing in cases ofresorption,as it leads to the avoidance of apical surgical procedures with a similar prognostic outcome.

\section{Acknowledgments}

The authors deny any conflicts of interest related to this study. 


\section{International Journal of Science and Research (IJSR) \\ ISSN (Online): 2319-7064}

Index Copernicus Value (2013): 6.14 | Impact Factor (2014): 5.611

\section{References}

[1] Ashwini T, Hosmani N, Patil C, Yalgi V. Role of mineral trioxide aggregate in management of external root resorption. J Conserv Dent 2013;16(6):579-581.

[2] Cehreli Z, Sara S, Uysal S, Turgut M. MTA apical plugs in the treatment of traumatized immature teeth with large periapical lesions. Dent Traumatol 2011;27:59-62.

[3] Dimitrova I, Kouzmanova Y. Marginal adaptation of calcium silicate-based materials used in furcal perforation repair: A comparative in vitro study. Int $\mathrm{J}$ of Science and Research 2015; 4(8): 750-5.

[4] Floratos S, Tsatsoulis I, Kontakiotis E. Apical Barrier Formation After Incomplete Orthograde MTA Apical Plug Placement in Teeth with Open Apex - Report of Two Cases. Braz Dent J 2013;24(2): 163-166.

[5] Fuss Z, Tsesis I, Lin S. Root resorption-diagnosis, classification and treatment choices based on stimulation factors. Dent Traumatol 2003;19:175-82.

[6] Gulabivala K, Patel B, Evans G, Ng Y. Effects of mechanical and chemical procedures on root canal surfaces. Endod Topics 2005;10:103-22.

[7] Gusiyska A. Periapical resorptive processes in chronic apical periodontitis: an overview and discussion of the literature. J of IMAB. 2014;20(5):601-5.

[8] Hachmeister D, SchindlerW, Walker 3rdW, ThomasD. The sealing ability and retention characteristics ofmineral trioxide aggregate in a model of apexification. J Endod. 2002;28(5):386-90.

[9] Ham K, Witherspoon D, Gutmann J, Ravindranath S, Gait T, Opperman L. Preliminary evaluation of BMP-2 expression and histological characteristics during apexification with calcium hydroxide and mineral trioxide aggregate. J Endod 2005;31(4):275-9.

[10] Holden D, Schwartz S, Kirkpatrick T, Schindler W. Clinical outcomes of artificial root-end barriers with mineral trioxide aggregate in teeth with immature apices. J Endod 2008;34:812-7.

[11] Holland R, de Souza V, Nery M, Faraco Jr I, Bernabé P, Otoboni Filho J, et al.Reaction of rat connective tissue to implanted dentin tube filled with mineral trioxide aggregate, Portland cement or calcium hydroxide. Braz Dent J 2001;12:3-8.

[12] Kabak Y, Abbott P. Prevalence of apical periodontitis and the quality of endodontic treatment in an adult Belarusian population. Int Endod J 2005;38(4):238-45.

[13] Katebzadeh N, Hupp J, Trope M. Histological periapical repair after obturation of infected root canals in dogs. J Endod 1999; 25:364-8.

[14] Leonardo M, Silva L, Leonardo R, Utrilla L, Assed S. Histological evaluation of therapy using a calcium hydroxide dressing for teeth with incompletely formed apices and periapical lesions. J Endod 1993;19:348-52.

[15] Mohammadi Z, Yazdizadeh M, Khademi A. Sealing ability of MTA and a new root filling material. Clin Pesg Odontol Curtitiba. 2006;2:367-71.

[16] Nelson-Filho P, Silva L, Leonardo M, Utrilla L, Figueiredo F. Connective tissue response to calcium hydroxide-based root canal medicaments. Int Endodon J 1999;32:303-11.

[17] Parirokh M, Torabinejad M. Mineral trioxide aggregate: A comprehensive literature review-Part III: Clinical applications, drawbacks, and mechanism of action. J Endod2010;36:400-13.

[18] Peters L, Wesselink P, Buijs J,Winkelhoff A. Viable bacteria in root dentinal tubules of teeth with apical periodontitis. J Endod2001;27(2):76-81.

[19] Porkaew P, Retief D, Barfield R, Lacefield W, SoongS. Effects of calcium hydroxide paste as an intracanal medicament on apical seal. J Endod1990;16(8):369-74.

[20] Rai R, Singbal K, Rathore V, Kariya P. Apical Barrier Formation after Orthograde MTA Placement in Teeth with Open Apex and periapical lesions - a case report. Sch J Dent Sci 2015; 2(2A):137-139.

[21] Raut A, Mantri V, Palekar A, Kamat S. Single step apexification with mineral trioxide aggregate (MTA)Case Reports. NJDSR 2012;1:28-2.

[22] Silva L, Nelson-Filho P, Leonardo M, Rossi M, Pansani C. Effect of calcium hydroxide on bacterial endotoxin in vivo. J Endod2002;28:94-8.

[23] Tanomaru-Filho M, Tanomaru J, Barros D, Watanabe E, Ito I. In vitro antimicrobial activity of endodontic sealers, MTA-based cements and Portland cement. J Oral Sci 2007;49:41-5.

[24] Torabinejad M, Hong C, McDonald F, Pitt Ford T. Physical and chemical properties of a new root end filling material. J Endod 1995;21:349-53.

[25] Trope M, Delano E, Orstavik D. Endodontic treatment of teeth with apical periodontitis: single vs. multivisit treatment. J Endod1999; 25:345-50.

[26] Vizgirda P, Liewehr F, Patton W, McPherson J, Buxton T. A comparison of laterally condensed gutta-percha, thermoplasticized gutta-percha and mineral trioxide aggregate as root canal filling materials. J Endod 2004;30:103-6. 